\title{
EDUCAÇÃO AMBIENTAL OU EDUCAÇÃO PARA O EMPREENDEDORISMO: RESPOSTAS PARA UM MUNDO COMPLEXO
}

Suzana Machado Padua ${ }^{1}$

\section{Resumo:}

No mundo de hoje, onde há uma demanda cada vez maior por recursos naturais e uma iniquidade social marcante, o processo educacional precisa ser radicalmente mudado. Ao invés de se educar para a aceitação do que vem pronto, numa expectativa de passividade, é preciso incentivar a inquietude e o inconformismo e fomentar o empreendedorismo, com ousadias em práticas que visem 0 respeito à vida e a tudo o que represente bens à coletividade. $A$ educação ambiental é uma dessas propostas de mudanças, que, como o desenvolvimento sustentável, surgiu em decorrência de crises causadas pelo modelo vigente. Porém, se a educação abrangesse todas as dimensões que deveria, não seriam necessários adjetivos para classifica-la, pois já incluiria as diversas áreas que levassem em conta o respeito à vida, prezando o que é socialmente justo e ecologicamente sustentável. Quem sabe assim o mundo teria mais chances de atingir patamares de evolução que nos deixasse com orgulho de dele fazer parte.

Palavras-chave:. Educação Ambiental; Empreendedorismo, Mudanças Paradigmáticas; Respeito à Vida.

\footnotetext{
${ }^{1}$ IPÊ - Instituto de Pesquisas Ecológicas. E-mail: suzana@ipe.org.br
} 


\section{Introdução}

Evidências de desarmonias no convívio dos seres humanos entre si e com a natureza têm sido crescentes em todo o planeta. O modelo de desenvolvimento predominante se caracteriza pelo acúmulo de bens, cujos impactos socioambientais são desproporcionais à consciência, ao conhecimento e à determinação para enfrentá-los. As crises se tornaram cada vez mais comuns e complexas com iniquidades sociais acentuadas e graves agressões à natureza. Impera a insustentabilidade que afeta, inclusive, os processos evolutivos que outrora ocorriam naturalmente de forma gradativa.

O final dos anos de 1960 e a década de 1970 foi um período marcado pela consciência de que o modelo desenvolvimentista predominante precisava ser repensado. Chamava a atenção o aumento de casos de poluições e contaminações do ar e das águas, o declínio ou desaparecimento de espécies, o desmatamento com consequências como alagamentos e deslizamentos de terras. Foi nesse contexto que surgiram buscas de novos caminhos como 0 desenvolvimento sustentável e a educação ambiental, entre outros, que visavam trazer maior harmonia ao planeta.

Em grande parte, a mudança de percepção se deu porque a realidade do mundo mudou. Até alguns séculos atrás, quando as condições ambientais se esgotavam, novas regiões passavam a ser exploradas. Mas, o mundo ficou pequeno, pois as fontes de recursos naturais que alimentam as demandas cada vez maiores da humanidade vêm desaparecendo. Não só ouve um acréscimo significativo da população mundial, como os anseios de consumo aumentaram em proporções desequilibradas ao que se encontra disponível na natureza para suprir as demandas.

O fato é que a insustentabilidade do momento atual se evidencia por toda parte. Mas, o que se passa na natureza nem sempre é percebido pela grande maioria, uma vez que a população humana se concentra cada vez mais em centros urbanos. Assim, o desafio se torna maior, pois é preciso sensibilizar o ser humano, que muitas vezes decide o destino das áreas naturais, mas que nem sempre tem ligação afetiva com a natureza.

Mas, motivar as pessoas a saírem de suas zonas de conforto e agirem para transformar realidades que não são mais desejáveis não é um feito simples. Pensar criticamente, analisar possibilidades e agir com base em novos parâmetros, são alguns dos aspectos que precisam ser abarcados pela educação. Infelizmente, estas não as premissas do ensino oferecido à grande maioria, que tende a podar a criatividade e a desincentivar o questionamento e a ação, e acaba gerando pessoas que aceitam a realidade como lhes é apresentada.

A educação ambiental difere neste sentido, pois desde que surgiu, adota princípios com o objetivo de "empoderar" o educando, de modo a que ouse buscar caminhos que visem harmonia, equidade e sustentabilidade da vida humana e não-humana. Sem dúvida, estas são características valiosas, mas o 
momento talvez seja o de se incentivar o espírito de empreendedorismo junto à área da educação ambiental, de modo a motivar inovação, ousadia e não aceitação de situações que desrespeitem a vida e, assim, estimule mudanças paradigmáticas que podem implantar modelos mais promissores que sejam pautados pela ética.

Mesmo que colocado de uma forma diferente, essa linha de pensamento condiz com que sugere Freire (1992, p.92), quando afirma:

$\mathrm{Na}$ verdade, toda vez que o futuro seja considerado como prédado, ora porque seja a pura repetição mecânica do presente, só adverbialmente mudado, ora porque seja o que teria que ser, não há lugar para o sonho, para a opção, para a decisão.

É isso que se precisa evitar no momento atual que urge mudanças radicais na forma com que o ser humano se relaciona entre si e com o ambiente a sua volta. Sachs (1986) expressa a necessidade de 'desconstruir para depois remontar', o que exige que se desarme de ideias pré-concebidas para se refletir sobre o que vale a pena preservar, deixando margem para que o novo possa se instaurar.

\section{Educação ambiental}

A educação deveria contemplar todos os aspectos do conhecimento e dos valores que ajudam a harmonizar a vida. Mas, as crises socioambientais mostraram falhas no processo educacional, pois deram margem à indagação sobre o tipo de educação que estava sendo oferecida para se ter resultados como os que se apresentavam. Foi neste cenário de crise que surgiu a educação ambiental (PADUA; SÁ, 2002).

De fato, o sistema educativo não tem sido capaz de formar pessoas com valores integradores e com motivação suficiente para assumirem responsabilidades e cuidados com bens públicos, que incluem as áreas naturais. Não há uma real valorização da vida que celebre as riquezas herdamos no planeta, sejam elas ambientais ou as diversidades culturais com todo o conhecimento acumulado no decorrer da história humana. Daí a atual tendência de se considerar cada vez mais a educação ambiental como um processo de educação para a cidadania, tendo em vista a necessidade da gestão pública nas questões socioambientais (PADUA; SÁ, 200202).

O aparecimento da educação ambiental se deu com princípios ambiciosos que visavam responder às necessidades dos tempos modernos. Na Carta de Belgrado de 1975, por exemplo, foi apontado um objetivo bem maior do que informar ou transmitir conhecimentos (CZAPSKI, 1998): 
... a juventude precisa receber uma nova educação, o que requer um novo tipo de relacionamento entre estudantes e professores, entre escola e comunidade, entre sistema educacional e a sociedade. É nesse sentido, que devem ser lançadas as fundações para um programa mundial de Educação Ambiental que torne possível o desenvolvimento de novos conhecimentos e habilidades, valores e atitudes, visando à melhoria da qualidade ambiental e, efetivamente, à elevação da qualidade de vida para as gerações presentes e futuras.

Observa-se que a dimensão era ampla e com intenções de aplicação prática, como se pode ver nos objetivos traçados em Tbilisi, então União Soviética, onde foi realizada a Primeira Conferência Inter-governamental de Educação Ambiental em 1977 (UNESCO-UNEP, 1978, p.24):

A educação ambiental, devidamente entendida, deveria constituir uma educação permanente, geral, que reage às mudanças que se produzem em um mundo em rápida evolução. Essa educação deveria preparar o indivíduo, mediante a compreensão dos principais problemas ambientais do mundo contemporâneo, proporcionando-lhe conhecimentos técnicos qualidades necessárias para desempenhar uma função produtiva, com vistas a melhorar a vida e proteger o meio ambiente, prestando a devida atenção aos valores éticos.

Mesmo que os objetivos iniciais da educação ambiental fossem mais ambientais do que socioambientais, o que se percebe é uma larga distância entre o que se pretende e o como o indivíduo é preparado para atuar. A educação, ao contrário de "empoderar" as pessoas a agirem e ousarem soluções inovadoras, tende a manter um padrão de obediência e de aceitação da realidade estabelecida. Há uma premissa, mesmo que não explícita, de que a pessoa não é capaz de transformar sua realidade. Ora, se essa for a tônica a ser aceita, não se terá um sujeito participante e protagonista do seu próprio destino, e menos ainda do destino do planeta. É nesse sentido que precisa haver uma transformação radical no processo educacional, que pode ir além do que propõe a educação ambiental em seu primeiro momento. É preciso introduzir avanços no estímulo ao empreendedorismo, que inclui a não aceitação do que é socialmente injusto e ambientalmente insustentável.

É verdade que a educação ambiental nunca parou de se transformar desde que surgiu. Em uma análise dos quase 20 anos que sucederam à reunião de Tbilisi, Sauvé (1996) descreveu as tendências predominantes, e como três termos são muitas vezes interpretados de maneiras diferentes e até contraditórias: 'ambiente', 'desenvolvimento sustentável' e 'educação ambiental'. Ambiente pode ser a natureza intocada e digna de reverência, ou um problema a ser resolvido. Desenvolvimento sustentável varia de uma consequência do neoliberalismo, confiando às grandes corporações e ao livre comércio o rumo a 
ser tomado, ou expressa uma busca de novos paradigmas nos quais a coletividade trabalha em prol de bens comuns. Educação ambiental significa desde a transmissão de conhecimentos com abordagens tecnicistas, até um processo de reflexão, cooperação, inclusão e fortalecimento comunitário, cujos objetivos visam benefícios coletivos. Esta variedade de interpretações faz com que se deva tomar cuidados ao empregar os termos para que o posicionamento do que se pretende fique claro.

Em vista da evidente insustentabilidade, Sachs (1986) lançou o conceito de eco-desenvolvimento, que posteriormente evoluiu para 'desenvolvimento sustentável'. A ideia básica é a necessidade de mudanças de postura frente ao crescimento econômico, que tem sido à tônica das decisões, e que vem colocando cada vez mais pressões sobre o ambiente natural e sobre as culturas não-incluídas no sistema capitalista. Porém, apesar da intenção inovadora de integrar preceitos éticos aos conceitos científicos, os termos "desenvolvimento", que pressupõe crescimento, e "sustentabilidade", que depende de um menor impacto possível, são incompatíveis e contraditórios em muitos aspectos, podendo, segundo Escobar (1992), ser interpretados como ainda pertencentes ao paradigma capitalista.

Todavia, Esteva e Reyes (1998:36) descrevem o papel da educação ambiental na construção de uma sociedade sustentável ao criar e fortalecer uma consciência ética que promova o respeito à vida e articule uma renovada visão do mundo, na qual prevaleçam valores que permitem uma relação harmônica e de longo prazo entre a humanidade e a natureza. Os autores apontam formas de se elevar o nível de compreensão entre os membros da sociedade sobre a complexidade e a gravidade dos problemas socioambientais, para que estes não sejam menosprezados ou percebidos como incapazes de promover mudanças. Acreditam na importância de se aportar elementos conceituais e práticos que permitam às sociedades regionais ampliarem seus níveis de participação política e social para formular propostas de desenvolvimento sustentável. Mencionam, ainda, o papel da difusão de conhecimentos e alternativas específicas que encorajem indivíduos e a coletividade a assumirem condutas e adotarem tecnologias coerentes com o desenvolvimento sustentável. Os autores defendem a ideia de se estreitar vínculos de solidariedade e respeito entre diversos grupos sociais na busca da construção de justiça econômica e, a partir daí, reforçar os esforços que visem romper a relação entre pobreza e depredação ambiental. Essas bases conceituais torna a educação ambiental um campo onde se cria uma nova cultura ambiental, que os autores concluem estar intimamente ligada à ética, pois incorpora caminhos que incluem todos os seres e aposta na transformação social com base em modelos inovadores de desenvolvimento.

Na perspectiva de Gaudiano (1998), a educação ambiental nos países desenvolvidos se baseia em perspectivas distintas daquelas dos países em desenvolvimento. Para os primeiros a preocupação sempre foi mais voltada à proteção da natureza, enquanto que nos países mais pobres a questão social 
tem sido incluída como prioridade, pois os programas priorizam o envolvimento comunitário e a inclusão social. E, como são os países menos abastados que em geral abrigam a maior concentração de biodiversidade, os desafios são maiores, e suprir as necessidades socioambientais exige esforços redobrados. Pela falta de recursos disponíveis para sua proteção e para iniciativas ambientais em geral, esses países acabam sofrendo perdas de áreas naturais, poluições, contaminações, desertificações e outros danos ambientais, que normalmente não chegam a se tornar problemas nos países ricos, por serem tratados antes de tomarem proporções de gravidade.

A educação ambiental introduz uma proposta de gestação de uma nova ética e de mudanças de comportamentos. Mudar comportamentos humanos é sempre um processo demorado que, de acordo com os princípios propostos pela educação ambiental, exige posturas éticas, solidárias e participativas. Neste sentido, considera-se que na educação ambiental a inclusão de valores é indispensável. Não basta saber. É necessário transformar os princípios que orientam as decisões políticas sobre as prioridades locais, regionais e nacionais, principalmente no que tange a educação para a cidadania. As pessoas precisam ser tocadas, de modo a despertarem sua sensibilidade, criatividade e sentido de coletividade. E mais, é necessário que desenvolvam capacidades que os permitam participar de decisões e os ensinem a se organizar para mudar o que não querem mais. Ser capaz de diagnosticar problemas, identificar causas e não só enfrentar as consequências, se pensar soluções criativas que transformem realidades que não se quer é parte dos atributos necessários neste momento. Talvez um dos maiores desafios seja estimular as pessoas a aceitarem opiniões divergentes e aprenderem a priorizar o que é melhor para a coletividade e não só para si próprios (PADUA, 2001; PADUA; SÁ, 2002).

Nesse sentido, a educação ambiental se torna chave porque chama a atenção para a importância de cada um contribuir para um mundo mais ético e para a sua responsabilidade de se engajar em processos que visam um bem maior, onde o respeito pela vida é a via principal de conduta (STAPP et al., 1996).

Brandão (1995, p.224) define poeticamente a educação ambiental como:

(...) um preparo profético de uma imensa abertura de nossas possibilidades de comunicação com a vida e os seres humanos. É um exercício antecipado de partilha, portanto, do desejo de ampliar até dimensões infinitas a vocação de convivência generosa, fraterna, entre os homens e entre os homens e todos os seres da vida.

A educação ambiental tem, assim, sido um campo de inovação que encoraja a inclusão de questões importantes como participação, justiça e sustentabilidade. Esta deveria ser a tônica da educação sem adjetivos, mas ainda não é o que se percebe. É por isso que a educação ainda precisa do complemento "ambiental", mesmo que esteja contribuindo para bem mais do que 
o ambiente. Trata-se de uma educação para a cidadania, que exige reflexões críticas e decisões participativas, de modo a aumentar as chances de se formar cidadãos capazes de escolherem seus destinos de uma maneira consciente.

\section{Educação para empreendedorismo}

A educação hoje deve se dedicar a formar empreendedores. Isso porque o mundo necessita de gente que ouse sonhar mudanças, que parta de utopias e que se sinta encorajada a implementar ideias criativas. As questões atuais são complexas, e não mais resolvíveis por quem pensa linearmente. É necessário que as pessoas ajam com energia e determinação, que almejem chegar a algo diferente do que veio pronto e que muitas vezes já não mais satisfaz.

Diversos autores descreveram o princípio de 'desconstruir' para depois 'remontar', que se inicia pelo caos da destruição do velho, com escolhas de novos caminhos emergindo de processos reflexivos (MORIN, 1996; SACHS, 1986). A ideia é que em meio às diferenças as pessoas e grupos conseguem identificar afinidades ou objetivos comuns, que acabam resultando na integração de atores, que passam a perceber possíveis áreas de convergência. As pessoas, neste processo, se desarmam de conceitos pré-concebidos e passam a decidir com consciência o que vale a pena manter, deixando margem para o novo se instalar.

Freire (1979) considera o ser humano inacabado, o que torna o processo educativo constante e contínuo. Segundo o autor, a reflexão deve ser parte inerente da educação, pois só assim o ser humano deixa de ser objeto e passa a ser sujeito. "Quando o homem compreende sua realidade, pode levantar hipóteses sobre o desafio dessa realidade e procurar soluções. Assim, pode transformá-la e com seu trabalho pode criar um mundo próprio: seu eu e suas circunstâncias" (FREIRE, 1979b, p.30).

Boff (1999, p.195) usou a palavra 'empoderamento' para definir "a criação de poder nos sem-poder ou a socialização do poder entre todos os cidadãos e reforço da cidadania ativa junto aos movimentos sociais". A educação ambiental é um caminho onde o potencial individual tem mais valor quando direcionado ao bem coletivo.

Já segundo Stapp et al. (1996), o 'empoderamento' se dá quando a educação permite que educador e educando participem de processos que os conscientizem de suas opções e os encorajem a agir, exercitando seu papel de cidadãos. "Precisamos desenvolver uma abordagem de aprendizagem que estresse a compreensão de risco e habilidades como pensamento crítico, resolução de problemas e trabalhos grupais" (STAPP et al., 1996, p.13).

Meadows (1997, p.16) considera a educação ambiental um meio de "aprendizagem de como gerenciar e melhorar as relações entre a sociedade humana e o ambiente, de modo integrado e sustentável". O fato é que ao promover câmbios na qualidade da visão de si mesma, a pessoa passa a ter um senso de sua inteireza quando em relação com o outro e com a natureza. Cada 
um deve descobrir seu potencial transformador, de modo a estimular o desenvolvimento de capacidades para solucionar problemas e para um engajamento efetivo em processos de mudança e de participação (STAPP et al., 1996).

Mas, a prática da participação não ocorre espontaneamente, segundo a opinião de Demo (1990, p.101):

... a participação é um processo histórico de conquista das condições de autodeterminação. Participação não pode ser dada, outorgada, imposta. Também nunca é suficiente, nem prévia. Participação existe se e enquanto for conquistada. Porque é processo, não produto acabado. Pela mesma razão é igualmente uma questão de educação de gerações.

Morin (1996) chama atenção para a importância de o ser humano perceber o sentido de liberdade permanente de escolha, o que desperta na pessoa seu senso de singularidade, de responsabilidade e de comprometimento consigo mesma, com a coletividade e com o meio ambiente. Esse despertar está ligado à compreensão da complexidade e da importância da incerteza, que ajudam a incluir os mais diversos aspectos e disciplinas. A visão complexa só pode ocorrer quando existe uma liberdade ampla que, por sua vez, depende de uma postura aberta (MORIN, 1996).

Deixar o novo brotar é papel do educador, que ao invés de controlar o processo de aprendizagem deve contribuir para que os indivíduos descubram suas próprias capacidades. As pessoas precisam perceber que são capazes de alcançar os resultados que desejam. Criar soluções para problemas que parecem incontornáveis, ousar sair da zona de conforto na qual a maioria prefere permanecer, e ampliar o escopo de visão do que pode ser alcançado e meios de como se chega a resultados que beneficiem a coletividade são alguns dos aspectos da nova educação que precisa ser instaurada, de modo a estimular o empreendedorismo que cada um traz consigo, mesmo que em graus diferenciados.

É preciso formar pessoas que não aceitem "não" como resposta. Pessoas que criem mecanismos de driblar os percalços que encontram quando se dedicam a alcançar o que desejam. Na verdade, é preciso antes propiciar ambientes onde as pessoas aprendam a sonhar, a imaginar alternativas para os problemas encontrados e coragem para buscar capacidades que os ajudem a criar soluções. Ao invés de moldar conformistas, a educação, seja ambiental ou direcionada ao empreendedorismo, deve formar pensadores ousados e estimulados a transformar realidades - e tudo isso permeado com ética. Aliás, bastaria a ética para que o mundo fosse mais harmônico e a vida devidamente respeitada. 


\section{REFERÊNCIAS}

BOFF, L. Saber cuidar: ética do humano - compaixão pela Terra. Petrópolis:

Vozes.1999

BRANDÃO, C.R. Em campo aberto. São Paulo: Cortês Editora. 1995.

CZAPSKI, S. A implantação da educação ambiental no Brasil. Brasília: MEC. 1998.

DEMO, P. Pobreza política. São Paulo: Cortez. 1990.

ESCOBAR, A. Reflections on 'Development'. Futures. V.4(5).pp.411-436, 1992. ESTEVA, J.; REYES, J. Manual del promotor y educador ambiental para el desarrollo sustentable. México: Secretaria de Medio Ambiente, Recursos Naturales y Pesca e Programa de las Naciones Unidas para el Medio Ambiente (PNUMA). 1998.

FREIRE, P. Educação como prática da liberdade. São Paulo: Editora Paz e Terra. 1992.

GAUDIANO, E.G. La profissionalización de los educadores ambientales: puntos críticos para una propuesta curricular. In: GAUDIANO, E.G.; GUILLÉN, F.C. (orgs.) Profesionalizar la Educación Ambiental? México: Universidad de Guadalajara, Secretaria de Medio Ambiente, Recursos Naturales y Pesca e Fundo de las Naciones Unidas para la Infancia - UNICEF. 1998.

MEADOWS, D. The limits to growth. In: NELISSEN, N.; STRAATEN, J.V.D.; KLINTERS L. (orgs). Classics in environmental studies. Utrecht, Holanda: International Books, pp.195-198, 1997a.

MEADOWS, D. Conceitos para se fazer Educação Ambiental. Brasília: IPÊ Instituto de Pesquisas Ecológicas, MEC, Secretaria do Meio Ambiente do Estado de São Paulo, UNESCO e UNICEF. Cadernos de Educação Ambiental. 1997b.

MORIN, E. Epistemologia da complexidade. In: Novos paradigmas, cultura e subjetividade. Porto Alegre: Artes Médicas. 1996.

PADUA, S. Educação Ambiental e Participação Comunitária: chaves para a conservação da biodiversidade. In: ROURE, M.; PADUA, S.M. (orgs.). Empreendedores sociais em ação. São Paulo: Cultura Editores. p.183-201, 2001.

PADUA, S.M.; SÁ, L.M.M. O papel da Educação Ambiental nas mudanças paradigmáticas da atualidade. Revista Paranaense de Desenvolvimento. $n$. 102, p.71-83, jan./jun. 2002.

SACHS, I. Espaços, tempos e estratégias do desenvolvimento. São Paulo: Vértice. 1986. 
SAUVÉ, L. Environmental education and sustainable development: a further Appraisal. Canadian Journal of Environmental Education. Volume 1, pp.7-34, 1996.

STAPP, W.; WALS, A.E.J.; STANKORB, S.L. Environmental education for empowerment: action research and community problem solving. lowa: Kenda//Hunt Publishing Company. 1996.

UNESCO/UNEP. Intergovernmental conference on environmental education - Tbilisi (USSR) 1978. 14-26 October 1977. Paris: ED/MD/49. 